\title{
¿Periodistas o productores de contenidos? La identidad profesional en los convenios colectivos de las empresas informativas
}

\author{
Carmen Fuente CoBO \\ Centro Universitario Villanueva (Madrid) \\ cfuentecobo@villanueva.edu
}

Recibido: 3 de diciembre de 2013

Aceptado: 19 de mayo de 2014

\section{Resumen}

En ausencia de un estatuto marco de la profesión periodística, los convenios colectivos de las empresas informativas son determinantes en la configuración del estatuto efectivo de los periodistas en España. Este artículo aborda la identidad de los profesionales de la información tal como aparece reflejada en los convenios colectivos del sector de empresas y medios informativos, a partir de la selección y descripción de 10 indicadores cuya presencia se analiza en más de 30 convenios sectoriales y particulares.

Palabras clave: Identidad profesional del periodista, convenios colectivos, empresa informativa, estatuto del periodista, estatutos de redacción

\section{Journalists or content producers? Professional identity and collective agreements in news media companies in Spain}

\begin{abstract}
In the absence of a frame-regulation of Journalism as a profession, the collective agreements adopted by media companies in Spain are crucial in shaping the actual status of journalists in this country. This article addresses the issue of professional identity of journalists, focusing on 10 indicators whose presence is discussed in more than 30 sectorial and particular collective agreements.

Keywords: Professional identity of journalists, collective agreements, news media companies, journalists legal statutes, editorial charters

\section{Referencia normalizada}

FUENTE COBO, Carmen (2014): “¿Periodistas o productores de contenidos? La identidad profesional en los convenios colectivos de las empresas informativas". Estudios sobre el Mensaje Periodístico. Vol. 20, Núm. 2 (julio-diciembre), págs.: 1045-1062. Madrid, Servicio de Publicaciones de la Universidad Complutense.
\end{abstract}

Sumario: 1. Los convenios colectivos en el sector de la información. 2. Sobre la identidad del periodista. 3. Sobre la actividad del periodista. 4. La identidad periodística en los convenios de las empresas informativas; 4.1. Indicadores de identidad profesional del periodista en los convenios colectivos de las empresas informativas; 4.2. Identificación diferenciada del periodista; 4.3. Perfiles, categorías y grupos profesionales en los que se integran los periodistas; 4.4. Ámbito de actividad diferenciado dentro de la empresa informativa; 4.5. Categorías profesionales excluidas de convenio; 4.6. Dedicación laboral del periodista; 4.7. Cláusula de conciencia; 4.8. Derechos de autor; 4.9. Derechos sobre la firma; 4.10. Derecho al secreto profesional;. 4.11. Estatuto de redacción. 5. Conclusiones. 6. Referencias bibliográficas.

\section{Introducción: Los convenios colectivos en el sector de la información}

El actual estatuto jurídico del profesional de la información en España se configura a partir de normas de ámbito estatal, normas de ámbito autonómico y normas que tienen su origen en la negociación colectiva entre los empresarios y los representantes de los trabajadores (Fernández, 2009: 414,415). En este contexto, los convenios colectivos en vigor tienen una doble naturaleza, a la vez de contrato, y de norma jurídica 
y fuente de Derecho, como indica Escobar Roca $(2002: 79,80)$, quien subraya su importancia para el estatuto de los periodistas, ya que contienen "la más amplia regulación de sus derechos y deberes en el seno de la empresa".

Si bien en Europa es habitual que los sindicatos de periodistas aborden tanto la defensa de los derechos laborales como la promoción de los derechos profesionales, mediante un doble sistema de convenio único colectivo que se complementa con convenios sectoriales (Díaz Arias, 2003: 10,11), en España no hay un convenio único que regule de manera general la relación laboral de los informadores. Y, por otra parte, los convenios de las grandes empresas y los convenios de sectores regulan las relaciones de todos los trabajadores, sean o no informadores. Por esta razón, concluye Escobar Roca, "la importancia del convenio colectivo como fuente propia del estatuto del periodista queda así notablemente desdibujada" (2002: 86).

La negociación colectiva en el sector de medios y empresas informativas es relativamente reciente. EI I Convenio Colectivo de la Prensa Diaria, suscrito en 2001, ha sido calificado como "sin duda, la norma convencional más importante de los periodistas españoles" en aquel momento (Escobar Roca, 2002: 81) y percibido como un logro sindical (Sánchez Illán, 2005), en la medida en que venía a poner fin a un vacío legal existente desde la derogación de la Ordenanza Laboral de Trabajo en Prensa de 1976, producida con la entrada en vigor del Estatuto de los Trabajadores de 1995.

El I Convenio fue firmado por CC.OO y UGT, de un lado, y por la patronal AEDE, de otro, y rechazado por el Sindicato de Periodistas de Cataluña por dejar fuera a las agencias informativas y a los periodistas a la pieza, incluidos inicialmente en el texto propuesto por CC.OO. y UGT (Escobar Roca, 2002: 81). Con todo, las diferencias más notables son las relativas a grupos y categorías profesionales. Los sindicatos, según los borradores estudiados por Labio Bernal (2001: 81-94), proponían organizar e identificar a los grupos profesionales de acuerdo con las distintas funciones de los trabajadores en un periódico: técnicos, personal de redacción (dentro del cual incluían tanto a redactores como a jefes de sección y ayudantes de redacción), personal de administración, personal de talleres, y personal de servicios generales. La AEDE, por su parte, impuso la clasificación por grupos profesionales, respondiendo a una jerarquía en la que se mezclan categorías profesionales, funciones y actividades diversas, de manera negativa para los periodistas.

El II Convenio Estatal dejó sin resolver la mayor parte de estas cuestiones, que fueron retomadas por los sindicatos durante la negociación del III Convenio Estatal de la Prensa Diaria. Dos de los principales temas de discusión fueron la inclusión de los periodistas a la pieza y los corresponsales, y la integración de las tareas profesionales propiamente informativas en grupos profesionales para los que se exigiera titulación universitaria. Con ello se pretendía evitar "los abusos que atribuyen menor nivel salarial a algunas tareas periodísticas" (Fernández, 2009: 256).

Estas y otras cuestiones aparecen reflejadas en el análisis de los convenios colectivos que constituyen el núcleo de este trabajo, que representa un primer esfuerzo por abordar la cuestión de la identidad profesional de los periodistas, tal como ésta aparece reflejada en este tipo de normas. Dada la imposibilidad de acometer la revisión de la totalidad de convenios suscritos en nuestro país en los últimos 40 años, se ha pro- 
cedido a una selección, a partir de los convenios colectivos estatales integrados en el epígrafe de Información y Comunicación del sistema CNAE (Clasificación Nacional de Actividades Económicas) y registrados en la base de datos del Registro de Convenios y Acuerdos Colectivos (RECGON), del Ministerio de Empleo y Seguridad Social. El periodo abarcado comprende principalmente los convenios suscritos entre 1996 y 2012, aunque también se incluyen documentos anteriores y posteriores, cerrándose la actualización de documentos en junio de 2013.

Por lo que se refiere a los convenios sectoriales, se han estudiado los tres suscritos en el sector de Prensa Diaria; los cuatro del sector de Prensa No Diaria; y el único convenio firmado hasta la fecha para el sector de radiodifusión comercial sonora. No existe un convenio equivalente para el sector de televisión privada. Entre los convenios particulares, se han incluido los de las agencias informativas EFE, Europa Press, Servimedia y Colpisa. Entre las empresas de edición de prensa diaria, se han seleccionado los convenios suscritos por las editoras de El País y El Mundo. En el ámbito de la televisión privada, se han estudiado los convenios aplicables al personal de las cadenas Cuatro -integrada primero en Sogecable y después en Mediaset- y Antena 3. En el de la radiodifusión privada, los de Unión Radio (La Ser) y Uniprex (Onda Cero). Y a todo ello se ha unido también el estudio del I Convenio Colectivo suscrito por la Corporación RTVE.

Este análisis se ha completado con el Estatuto de la Profesión Periodística de 1967 y las dos principales propuestas debatidas hasta la fecha para reemplazar dicha norma preconstitucional por una más actual, así como la Ordenanza Laboral de Trabajo en Prensa de 1976. En total, se han estudiado 31 convenios colectivos, más los textos de referencia indicados en este párrafo.

\section{Sobre la identidad del periodista}

Quién es periodista y quién no, cómo se accede a la profesión y en qué consiste la actividad desarrollada por los periodistas es, sin duda, de uno de los temas más polémicos de entre todos los que han permanecido abiertos en nuestro país tras la transición democrática. Basta con repasar los puntos de vista presentes en el discurso de los propios periodistas -por ejemplo, con motivo de los debates parlamentarios desarrollados en 1994 y 2004 en relación con tres iniciativas legislativas que afectaban de lleno al ejercicio profesional-, para comprobar que la cuestión profesional sigue siendo una cuestión abierta y de difícil solución en nuestro país (Suárez y Jiménez, 2012).

Sin entrar a considerar en qué medida la ausencia de un estatuto de la profesión periodística pueda constituir una "anomalía democrática" (Díaz Nosty, 2011: 42) y sin tratar de elucidar si el sistema de acceso a la profesión sin restricción ni acreditación previa es mejor o peor que la exigencia de acreditaciones previas, como exigía el estatuto de la Profesión Periodística de 1967 o las restricciones a posteriori en forma de cualificación definitiva tras un periodo de ejercicio profesional, como se establece en algunos países de nuestro entorno (Carrillo, 1993: 73-75), lo cierto es que desde hace más de cuatro décadas todos los intentos de abordar un estatuto jurídico para el profesional del periodismo han fracasado debido fundamentalmente a la imposibilidad de ponerse de acuerdo en la definición de periodista. Esta dificultad fue una de las cla- 
ves del fracaso de la Proposición de Ley de Estatuto de la Profesión de Periodista (PLEPP) basado en el texto elaborado por el Foro de Organizaciones de Periodistas (de cuyo consenso se descolgó posteriormente la FAPE), y fue también el principal escollo contra el que se estrellaron los posteriores esfuerzos de la FAPE y el Colegio de Periodistas de Cataluña para lograr el consenso de toda la profesión en torno a un nuevo borrador (Olmos, 2011: 997). En el desenlace negativo de uno y otro proyecto fueron coadyuvantes los empresarios de medios, frontal y unánimemente opuestos al primer borrador del FOP y abiertamente desinteresados en el caso del segundo borrador comentado (Olmos, 2011:997).

Cabría preguntarse, también, en qué medida han influido en la falta de acuerdo algunas posiciones extremas de defensa de la titulación específica y la colegiación como condiciones únicas y exclusivas para acceder a la profesión de periodista (Real Rodríguez, 2005), posición irreconciliable no solamente con la contenida en la PLEPP, sino también con las más abiertas y posibilistas barajadas por la FAPE (Real Rodríguez, 2006: 341,342). Por otra parte, la insistencia de algunos defensores de la titulación específica no está exenta, en ocasiones, de contradicciones derivadas de la multiplicación de oferta formativa en nuestro país. Esta diversificación de la oferta formativa ha llevado a algunos a proponer que, junto con la titulación específica en Periodismo, pueda considerarse también como titulaciones válidas para ser periodista las de Licenciado en Comunicación Audiovisual o en Publicidad (Fernández Areal, 2012), pero no otras titulaciones, lo que no deja de suponer una arbitrariedad ciertamente discutible.

En cualquier caso, da la impresión de que el debate sobre la titulación específica como vía de acceso a la profesión ha quedado superado por los hechos, ya que desde hace años la titulación universitaria de periodista se ha impuesto como un requisito, si no legal, sí de hecho en la contratación de profesionales para las áreas de redacción de las empresas de medios. En el año 2000 , el $82,2 \%$ de los profesionales que trabajaban en tareas periodísticas disponían de titulación específica (licenciatura en Periodismo o denominaciones afines, o procedían de las extintas Escuelas de Periodismo) (Canel et al., 2000), porcentaje que incluso ha aumentado en los últimos años hasta situarse en un 92,4\% en 2012, de acuerdo con los datos contenidos en el informe de la APM para ese año.

Por otra parte, es indudable que una parte sustancial del debate sobre la idoneidad e identidad del profesional de la información se sostiene sobre una realidad mediática caracterizada por la existencia de un sujeto profesional, el periodista, que hasta ahora ha venido realizando su actividad principalmente a través de un sujeto organizado, las empresas de medios, vinculados ambos por medio de una relación laboral. Pero algunos signos parecen indicar que avanzamos hacia una reestructuración y reorganización de la mediación profesional de los periodistas, al menos parcial, canalizada al margen de las estructuras organizativas tradicionales y hecha posible gracias a la creciente autonomía que las tecnologías digitales e internet provocan en cada eslabón de la cadena informativa (Muro, 2010). En este escenario de creciente desintermediación, hay quienes profetizan el fin del periodismo profesional y el advenimiento de una cultura ciudadana mediática. Para evitar la tentación del pesimismo y los lamentos 
anticipados por la muerte del periodismo, autores como Kovach y Rosenstiel (2010) reclaman situar la atención no tanto en el quién -el periodista o su alternativa, el ciudadano armado de medios electrónicos- cuanto en el qué y en el cómo, es decir, en la actividad desarrollada en torno a lo que denominamos periodismo y en la función de éste. Para estos autores, la misión del periodismo de dotar de sentido a una realidad inabarcable no solamente no ha desaparecido, sino que es aún más necesaria en este mundo saturado de ruido, en el que resulta tan difícil distinguir la verdad de la mentira, lo relevante de lo anodino.

Aquí, en el terreno del cómo y del método, es decir, en el ámbito de esa "verticalidad afectiva" (Suárez Villegas, 2009: 123) configurada en torno a la ética y los estándares profesionales, algunos autores proponen distinguir entre diferentes tipos de periodistas en función de la actividad desarrollada pero, sobre todo, del compromiso que adquiere cada uno con una misión específica vinculada a dicha actividad (Ugland y Henderson, 2007: 15,16). No es lo mismo, se apunta, la persona que difunde información valiosa para otros pero lo hace de manera esporádica, que el profesional que busca, elabora y difunde información de manera más habitual, deliberada y principal. $\mathrm{Y}$ tampoco es igual este periodista formalmente correcto pero de segundo nivel, que no adquiere más compromiso que el de la veracidad, que los periodistas de primer nivel, identificados como aquellos comprometidos con formas especialmente virtuosas de buscar y difundir información, en línea con la tradición más elevada de la profesión, tal como aparece expresada en los códigos deontológicos. Son estos últimos, los periodistas de primer nivel, los que han tratado de sostener su diferenciación a partir de elementos como la titulación, la experiencia profesional o la pertenencia a grandes medios periodísticos pero, como señalan Ugland y Henderson, "son sus acciones las que definen su trabajo, no esas credenciales periféricas. El debate en este terreno está a menudo sesgado por estas características del modelo experto, cuando lo que realmente importa -de hecho, lo único que importa-son los estándares de práctica profesional que siguen los periodistas en su búsqueda y difusión de noticias" (2007: 16).

Dejando al margen la prospectiva, hay un cierto consenso acerca de la existencia de una serie de valores que comparten los periodistas de todo el mundo aunque puedan señalarse diferencias culturales entre unos sistemas y otros (Roses y Farias, 2013: 175,176). Y, aunque sea necesaria más reflexión sobre las ideologías profesionales de los periodistas (Humanes, 2003), el núcleo cultural de la identidad periodística, homogeneizada como consecuencia de los procesos de globalización, está integrado por los conceptos de autonomía -principalmente en el seno de las organizaciones editorase independencia intelectual (Hanitzsch et al, 2012: 474). Esta "ideología de la independencia", como la denomina Calleja (2000: 19), está también presente de manera sustantiva en el discurso profesional de los periodistas españoles como valor profesional por excelencia (Del Val, 2000: 154).

\section{Sobre la actividad del periodista}

El principio de independencia intelectual como valor constitutivo de la identidad profesional del periodista está indisociablemente unido al tipo de trabajo que éste realiza, que "está presidido por un indudable componente intelectual, que ni los poderes 
públicos ni las empresas de comunicación pueden olvidar", como proclama la exposición de motivos de la LO 2/1997. Informar es, sobre todo y por encima de todo, una actividad de carácter eminentemente intelectual que, sin embargo, no llega a configurarse como profesión liberal principalmente porque -al menos en el modelo de intermediación vigente con carácter general hasta nuestro días- los informadores no se relacionan directamente con el sujeto universal del derecho a la información, sino que lo hacen a través de un sujeto organizado que es la empresa informativa, con la que el sujeto cualificado establece relaciones laborales (Díaz Arias, 2003: 3) cuyo objeto es precisamente la propia actividad informativa (Escobar de la Serna, 1997: 23).

La relación entre el carácter intelectual de la actividad informativa y la peculiar situación del periodista en el seno de la empresa informativa que es, a su vez, una empresa ideológica, se caracteriza, así pues, por la existencia de una inevitable tensión entre la independencia connatural al tipo de actividad que realiza el informador, y el poder de dirección de la empresa. Este tema de la independencia y subordinación de los informadores respecto al poder de dirección de las empresas es el problema central del contrato de trabajo del informador, señala Soria (1989: 78). Es la desobediencia de ciertos trabajadores muy cualificados o profesionales titulados ante el temor al descrédito profesional que se seguiría de la aplicación de las órdenes superiores [...]" (Soria, 1989: 81). Para Díaz Arias, la doctrina sobre la consideración de las empresas informativas como empresas de tendencia implica que "son unas muy peculiares empresas de tendencia porque el núcleo de sus empleados son titulares de un derecho fundamental de la misma esencialidad que el del empresario" (2003: 18). Esto lleva al autor a proponer algunas reglas para equilibrar derechos profesionales y obligaciones laborales de los informadores, que podrían inspirar tanto las normas (legales, estatutarias, convenios colectivos) como la resolución de los conflictos por los tribunales. Entre otras, propone la retención plena de su derecho a la libertad de expresión como ciudadano fuera de su relación laboral; la cláusula de conciencia; el establecimiento del derecho fundamental a la información y las normas deontológicas como límites a las directrices técnicas del medio; y la participación de los periodistas en el poder editorial a través de Consejos de Redacción (Díaz Arias, 2003: 19,20).

Azurmendi, por su parte, opina que aunque algunos entienden que la naturaleza misma de las actividades informativas es incompatible con su integración laboral, se puede admitir una relación laboral para la realización profesional de una actividad comunicativa, pero salvaguardando el carácter especial que tiene, por medio de instrumentos como la cláusula de conciencia, el secreto profesional y los derechos de autor e integrando de manera complementaria y, como contrapeso, los estatutos de redacción (2001: 225 y 226).

\section{La identidad periodística en los convenios de las empresas informativas}

¿Qué significa ser periodista en una empresa informativa? ¿Cómo se concreta la identidad periodística en la norma central que regula y ordena las relaciones laborales en el seno de la empresa informativa? Como se ha apuntado, existen una serie de parámetros o indicadores cuya presencia en los convenios colectivos permite extraer conclusiones acerca de la caracterización del periodista y de su trabajo. 


\subsection{Indicadores de identidad profesional del periodista en los convenios colecti- vos de las empresas informativas}

1. Identificación del periodista como profesional diferenciado dentro de la empresa informativa.

2. Escala profesional propia y específica de los periodistas, con categorías, grupos, perfiles y puestos diferenciados de otros existentes en la empresa.

3. Existencia de un ámbito de actividad periodística (Redacción) diferenciado de otras áreas de actividad de la empresa.

4. Figuras profesionales periodísticas excluidas de convenio.

5. Contenido de la prestación laboral del periodista: jornada y horarios.

6. Inclusión del derecho a la cláusula de conciencia dentro de los contenidos del convenio.

7. Inclusión de los derechos de autor dentro del convenio.

8. Inclusión de los derechos sobre la firma dentro del convenio.

9. Inclusión del secreto profesional dentro del convenio.

10. Existencia de un Estatuto de Redacción vinculado al convenio colectivo, y/o reconocimiento de órganos de representación profesional (comités de redacción).

\subsection{Identificación diferenciada del periodista}

Siguiendo la definición y condiciones para el ejercicio de la profesión de periodista contenidas en el Estatuto de la Profesión Periodística de 1967, la Ordenanza Laboral de Trabajo en Prensa de 1976 describía a los periodistas titulados como "aquellos profesionales que, en posesión del título correspondiente, expedido por la Escuela Oficial de Periodismo y/o Facultad de Ciencias de la Información, e inscritos en el Registro Oficial de Periodistas, realizan trabajos propios de su competencia profesional" (art.17). Se exigía esta condición de periodista titulado para desempeñar las funciones de subdirector, redactor-jefe, jefe de sección y redactor.

Pero tras el cambio de régimen, la imposibilidad de llegar a un acuerdo para la aprobación de un estatuto de la profesión periodística que pudiera reemplazar al de 1967, actuando como referente en el ámbito laboral, ha generado un clima de orfandad que se traslada a los convenios del sector, en los que observamos resistencias importantes a definir la figura del periodista o, cuando menos, a identificarle como un sujeto diferenciado dentro de la organización.

Como puede observarse en las tablas 1 y 2 , ninguno de los convenios analizados presenta y define la figura del periodista, a pesar de que en varios se utiliza el término como elemento para caracterizar determinados perfiles profesionales.

\begin{tabular}{|c|c|c|c|}
\hline CONVENIO & $\begin{array}{l}\text { Aparece el término } \\
\text { "periodista" }\end{array}$ & $\begin{array}{l}\text { Se define el término } \\
\text { "periodista" (quién es } \\
\text { periodista) }\end{array}$ & $\begin{array}{c}\text { Se exige titulación de } \\
\text { periodista }\end{array}$ \\
\hline $\begin{array}{l}\text { III Convenio estatal de } \\
\text { prensa diaria }\end{array}$ & $\begin{array}{l}\text { Sí, pero lateralmente (como } \\
\text { requerimiento de cualifica- } \\
\text { ción para determinadas } \\
\text { categorías laborales) }\end{array}$ & NO & $\begin{array}{l}\text { Los redactores B } \\
\text { deben ser "periodistas } \\
\text { titulados" }\end{array}$ \\
\hline
\end{tabular}




\begin{tabular}{|c|c|c|c|}
\hline $\begin{array}{l}\text { Convenio estatal de } \\
\text { prensa no diaria }\end{array}$ & NO & NO & $\begin{array}{lr}\text { Los } & \text { redactores } \\
\text { "titulados" } & \text { perciben } \\
\text { un plus de titularidad } \\
\end{array}$ \\
\hline $\begin{array}{l}\text { I } \quad \begin{array}{c}\text { convenio } \\
\text { radiodifusión }\end{array} \\
\text { de }\end{array}$ & $\mathrm{NO}$ & NO & $\mathrm{NO}$ \\
\hline
\end{tabular}

\begin{tabular}{|c|c|c|c|}
\hline CONVENIO & Aparece el término "periodista" & $\begin{array}{c}\text { Se define el término } \\
\text { "periodista" (quién es } \\
\text { periodista) }\end{array}$ & $\begin{array}{l}\text { Se exige titulación de } \\
\text { periodista }\end{array}$ \\
\hline Convenio EFE & $\begin{array}{l}\text { SÍ pero con carácter adjetivo, para } \\
\text { describir puestos y perfiles } \\
\text { incluidos en la escala profesional } \\
\text { de la agencia (p.ej., redactor jefe: } \\
\text { "periodista que coordina la } \\
\text { redacción y/e edición } \\
\text { informativa". }\end{array}$ & NO & $\begin{array}{l}\text { NO, pero la titulación } \\
\text { en Periodismo puntúa } \\
\text { por delante de otras en } \\
\text { el sistema interno de } \\
\text { promoción salarial y } \\
\text { profesional. }\end{array}$ \\
\hline Colpisa & $\begin{array}{l}\text { SÍ, pero solamente como } \\
\text { requerimiento de cualificación de } \\
\text { las categorías profesionales }\end{array}$ & NO & $\begin{array}{l}\text { Los redactores de nivel } \\
\text { B deben ser } \\
\text { "periodistas titulados" }\end{array}$ \\
\hline Europa Press & $\begin{array}{l}\text { SÍ, pero solamente como } \\
\text { requerimiento de cualificación de } \\
\text { figuras profesionales }\end{array}$ & NO & $\begin{array}{l}\text { - Definición de la } \\
\text { categoría profesional } \\
\text { de redactor como "el } \\
\text { periodista debidamente } \\
\text { titulado o acreditado" } \\
\text { - También se exige } \\
\text { titulación específica de } \\
\text { periodista para la } \\
\text { categoría profesional } \\
\text { de "periodista } \\
\text { multimedia" }\end{array}$ \\
\hline El País & $\begin{array}{l}\text { A partir del XVII Convenio } \\
\text { (2005), la Ordenanza Laboral de } \\
\text { Trabajo en Prensa deja de ser el } \\
\text { referente para las figuras y grupos } \\
\text { profesionales, y desaparece el } \\
\text { término de periodista como } \\
\text { identificador profesional }\end{array}$ & NO & $\begin{array}{l}\text { A partir del XVII } \\
\text { Convenio desaparece } \\
\text { el plus de titulación }\end{array}$ \\
\hline El Mundo & $\begin{array}{l}\text { A partir del V Convenio (1998), } \\
\text { la Ordenanza Laboral de Trabajo } \\
\text { en Prensa deja de ser referente. } \\
\text { El término "periodista" aparece } \\
\text { desde entonces con carácter } \\
\text { adjetivo, para describir puestos y } \\
\text { perfiles profesionales }\end{array}$ & NO & \\
\hline Corporación RTVE & $\begin{array}{l}\text { NO, pero en el Estatuto de } \\
\text { Información aparece como } \\
\text { concepto sustitutivo el de } \\
\text { "Profesional de la información } \\
\text { audiovisual" }\end{array}$ & $\begin{array}{l}\text { SÍ el de profesional de } \\
\text { la información } \\
\text { audiovisual }\end{array}$ & $\begin{array}{llr}\text { Prioridad } & \text { a } & \text { los } \\
\text { licenciados } & & \text { en } \\
\text { Ciencias de } & \text { la } \\
\text { Información } & \\
\text { (Periodismo o Imagen) } \\
\text { para la contratación } \\
\text { como redactores }\end{array}$ \\
\hline Cuatro & NO & $\mathrm{NO}$ & $\mathrm{NO}$ \\
\hline Antena $3 \mathrm{TV}$ & $\mathrm{NO}$ & $\mathrm{NO}$ & $\mathrm{NO}$ \\
\hline Unión Radio & $\mathrm{NO}$ & $\mathrm{NO}$ & $\mathrm{NO}$ \\
\hline Onda cero & NO & $\mathrm{NO}$ & $\mathrm{NO}$ \\
\hline
\end{tabular}


Con la excepción de la Corporación RTVE, cuyo Estatuto de Informativos incluye y define el concepto próximo de "profesional de la información audiovisual", el resto de los convenios rehúye definir el término "periodista", si bien en algunos casos se utiliza para definir y calificar los puestos y perfiles profesionales propios del área de Redacción, por ejemplo cuando en el convenio de EFE se define al redactor jefe como "el periodista que coordina la redacción y/o edición informativa", o al editor como "el periodista que se ocupa de la supervisión y edición, en último término, de aquellas noticias que le son encomendadas".

Por otra parte, asistimos desde hace años a una evolución natural de los perfiles profesionales, evidente sobre todo en el sector audiovisual, donde la transformación y desaparición de determinados perfiles y la aparición de otros nuevos, viene acompañada por una polivalencia creciente de los profesionales de la información. Esta reordenación de perfiles profesionales afecta también a la definición del concepto de periodista, que se amplía para abarcar nuevos procesos y tareas, sin verse afectado el núcleo de la identidad profesional.

En el ámbito de la radio, señalan López Vidales y Ortiz Sobrino (2011) que la figura que más cambios ha experimentado es la de redactor, que ha incorporado nuevas competencias y mayor polivalencia, aunque los perfiles multimedia son todavía escasos en este medio. El proceso más ambicioso de acomodación de los convenios colectivos a la nueva realidad profesional dentro de este sector es el abordado por Radio Nacional en el marco de reordenación normativa emprendido en 2006 por RTVE, que incluyó una nueva clasificación profesional centrada especialmente en la reducción del número de perfiles y categorías profesionales y la incorporación de una mayor polivalencia en sus definiciones. En los medios públicos catalanes, y especialmente en la televisión pública existe ya desde hace años esa figura del periodista polivalente definida como "informador", que graba imágenes, las edita y las deja listas para ser emitidas. Esta figura se ha consolidado fundamentalmente, según un estudio, en los medios en línea, en grandes empresas informativas y en medios de reciente creación (Scolari, 2008: 51-54).

El ámbito de la televisión es el que presenta mayores dificultades para acotar las tareas estrictamente informativas dentro de procesos en los que el componente técnico es muy elevado. Uno de los intentos más notables para resolver la problemática generada por esta realidad es el que se materializó en el Estatuto de Información de la Corporación RTVE. Rafael Díaz-Arias, que participó en la Comisión redactora del mismo, apunta como novedad el que dicho Estatuto define con carácter general el titular de los derechos y deberes, creando una nueva figura, la de "profesional de la información audiovisual", que no aparece delimitada con referencia a categorías laborales ni exigir una adscripción a áreas específicas, puesto que el Estatuto no regula relaciones laborales. Se trata, por tanto, de una vía de definición de identidad profesional que va paralela a la del convenio colectivo y a las categorías laborales contenidas en el mismo, pero del que es complementaria (2008: 14).

En este Estatuto, son profesionales de la información audiovisual los "profesionales del periodismo, la imagen o el sonido que obtienen, elaboran y difunden de forma directa los contenidos informativos divulgados por las empresas de la Corporación 
RTVE, tanto a través de los soportes multimedia e interactivos u otros semejantes que se puedan derivar del desarrollo de las nuevas tecnologías de la información, con vinculación directa con la Corporación, cualquiera que sea su categoría o nivel de responsabilidad" (art.3).

\subsection{Perfiles, categorías y grupos profesionales en los que se integran los perio- distas}

En España, el sistema tradicional de categorías profesionales consagrado por la normativa preconstitucional sigue presente en algunos convenios colectivos. La Orden de 24 de septiembre de 1968, dictada en desarrollo del art.48 del Estatuto de la Profesión Periodística de 1967, indicaba que la calificación laboral del periodista podía adoptar las modalidades siguientes: redactor, redactor de libre disposición, jefe de sección, redactor jefe y subdirector. Estas modalidades aparecían definidas también en la Ordenanza Laboral de Trabajo en Prensa. Y, como se ha señalado, siguen presentes en diferentes convenios colectivos actuales, caracterizando de manera propia y diferenciada puestos, actividades, funciones y tareas que habitualmente se entienden como propias de periodistas.

Con todo, la organización por categorías profesionales está siendo progresivamente reemplazada por la definición de grupos profesionales en los que se integran funciones similares con parecidas aptitudes o titulaciones profesionales. La cualificación profesional y, con ella, la integración en unas determinadas bandas salariales, se obtiene mediante la adscripción a uno de estos grupos profesionales en los que se entremezclan diferentes tipos de tareas y categorías profesionales.

La mayor parte de los convenios que han optado por la clasificación por grupos profesionales utilizan un doble sistema de clasificación: por grupos profesionales generales, en los que se integran todos los trabajadores en función de criterios definidos de igual forma para todas las categorías, perfiles y puestos susceptibles de encajar dentro de cada grupo; y por áreas de actividad. Esta doble clasificación permite mantener la diferenciación de la actividad informativa, pero tiene el inconveniente de la unificación y estandarización de los criterios de adscripción al grupo, dificultando la singularización del periodista. Este es el modelo seguido por los convenios estatales adoptados primero en el sector de prensa diaria y luego parcialmente replicado en los de prensa no diaria y radio privada. El establecimiento de requerimientos comunes para grupos profesionales que en realidad ni son ni pueden ser homogéneos en su composición, lleva a disfunciones como la de exigir formación de mayor nivel o especialización para determinadas categorías profesionales (Redactor B), que las requeridas para otros grupos con mayor nivel de responsabilidad y retribución, como sucede en los convenios estatales de prensa diaria.

\section{4. Ámbito de actividad diferenciado dentro de la empresa informativa}

Pueden distinguirse cuatro tipos de organizaciones en función de la estructura descrita en los convenios colectivos.

- En primer lugar, las empresas de perfil más periodístico identifican un área diferenciada de actividad denominada generalmente Área de Redacción o Área 
de Información, cuya función se relaciona directa y expresamente con la búsqueda, elaboración y difusión de información, destacando especialmente la definición que proporciona la agencia EFE para su División de Información o RTVE para el área identificada como "Información". En el caso de la agencia EFE, el convenio indica que la División de Información "reúne a los profesionales que tienen como objetivo fundamental de su trabajo recoger, elaborar, editar, seleccionar y clasificar, siempre bajo criterios periodísticos, aquella información, de todo tipo y en cualquier soporte, susceptible de ser comercializada por la Agencia EFE [...]" (art.16). La CRTVE, por su parte, incluye en el grupo profesional denominado Información a "quienes efectúan en RTVE las tareas de búsqueda, elaboración, tratamiento adecuado, redacción y emisión de las noticias y acontecimientos de actualidad, que constituyen el contenido de los programas de radio y televisión que tienen la calificación de informativos".

- En un segundo grupo se integran las empresas que identifican un área de Redacción de perfil periodístico aunque dicha área no llega a definirse de manera precisa en los convenios colectivos, lo que puede dar pie a que dicho perfil periodístico termine desdibujándose, especialmente si tampoco aparece dibujada con claridad la figura del periodista. En el caso de la empresa editora del diario El País, por ejemplo, el convenio alude en diferentes artículos al Área de Redacción, pero ésta no aparece definida.

- En un tercer grupo se incluyen las empresas que atribuyen al área redaccional la actividad de producir contenidos, sin distinguir el tipo o carácter de los mismos. Es el caso, por ejemplo, de los convenios estatales de prensa diaria, prensa no diaria y radio comercial, o el de empresas como Unión Radio o Uniprex (Onda Cero). Así, el III Convenio Estatal de Prensa Diaria Identifica tres Áreas de Actividad, la segunda de las cuales es el Área Informativa / Redacción, que es definida de la siguiente manera: "Se integran en esta área de actividad aquellos puestos cuya misión es la producción de contenidos en papel o en cualquiera otro soporte así como para su transmisión por medios electrónicos".

- En un cuarto grupo podríamos incluir a todas aquellas empresas que no incorporan sistema de clasificación basado en áreas de actividad o en el que éstas aparecen completamente desdibujadas. Entran en este grupo las empresas privadas de televisión Cuatro y Antena 3.

\subsection{Categorías profesionales excluidas de convenio}

Como ya vimos más arriba al referirnos a los sistemas de clasificación profesional, habitualmente el Director suele tener contrato de alta dirección y está incluido, por tanto, dentro de las relaciones laborales de carácter especial. La figura del subdirector, por su parte, no está claramente definida y en algunos casos se incluye dentro de los convenios y en otros queda excluida. La exclusión se está extendiendo progresivamente a cada vez más profesionales, bien por ampliación del abanico de puestos directivos o porque se aplican variables no contempladas en convenio, según pone de manifiesto un estudio realizado sobre 25 convenios colectivos del sector y cuyos resultados publicaba la revista Cuadernos de Periodistas (marzo 2010). 
La discusión de mayor calado en cuanto al alcance de los convenios colectivos se refiere a la figura de los colaboradores y, de manera más concreta, los denominados "periodistas a la pieza". La problemática relativa a estos profesionales es el núcleo central de la propuesta de Ley de Derechos Laborales de los Periodistas generada por el Foro de Organizaciones de Periodistas en marzo de 2001, que no llegó a ser tramitada. En ella se define a los periodistas a la pieza como "aquellos profesionales que tienen por ocupación principal y remunerada la obtención, elaboración, tratamiento y difusión por cualquier medio de información de actualidad, en formato literario, gráfico, audiovisual o multimedia, en virtud de encargo regular de una o varias empresas y siguiendo las instrucciones básicas de las mismas" (art.3), y se plantea el que dicha figura quede cubierta por relación laboral formalizada por escrito, indicando en el contrato el tipo de trabajos solicitados, la remuneración de los mismos, etc.(art.4).

La mayoría de los convenios colectivos analizados excluyen de su ámbito de cobertura a los periodistas a la pieza. Algunos excluyen también otras figuras. Por ejemplo, el de Europa Press excluye a los delegados, subdirectores, redactores jefes adjuntos al director, redactores jefes y jefes de sección. Colpisa deja fuera, por una parte, al director, los subdirectores y los redactores-jefes, a los que asimila a "altos cargos"; y, por otra, a los corresponsales y colaboradores, independientemente de que mantengan una relación continuada con la empresa.

\subsection{Dedicación laboral del periodista}

Se trata de un indicador de carácter tal vez más "formal", por cuanto se refiere a los condicionantes temporales de la actividad periodística, que aparece caracterizada habitualmente como trabajo "a tarea". Díaz Arias señala éste como uno de los rasgos que delimitan la prestación laboral del informador: "Lo que el trabajador debe no es tiempo de trabajo, sino el trabajo prestado durante un cierto tiempo" (2003: 24).

La mayor parte de los convenios reflejan esta peculiaridad del trabajo que tiene como contenido la actualidad informativa, aunque algunos la refieren al conjunto de la actividad de la empresa, como marco en el que se integran los acuerdos relativos a pago de horas extraordinarias, fines de semana, periodos vacacionales diferenciados, etc. Este es el caso del convenio sectorial de prensa diaria, en el que se indica que "al no permitir la naturaleza de la actividad periodística determinar un horario rígido de trabajo, cada miembro de la redacción [...] tendrá asignado un horario básico". En el de EFE se hace referencia a "la naturaleza de la actividad de la Empresa" para justificar la necesaria flexibilidad que deben tener los horarios y calendarios de fiestas.

Especial mención merecen los convenios colectivos de El País y Europa Press, que definen de manera explícita la dedicación laboral de los periodistas como "trabajo a tarea", una vez cumplida la cual, acaba la jornada.

\subsection{Cláusula de conciencia}

Son escasos los convenios que recogen este derecho de los periodistas, bien porque no lo abordan de ninguna manera -es el caso del convenio estatal de radio comercial y los de las empresas privadas audiovisuales- o bien porque, de manera explícita o implícita, remiten a lo que pueda encontrarse desarrollado en los estatutos de redacción de 
las empresas que cuentan con ellos. Dentro de este segundo grupo, la cláusula de conciencia no aparece contemplada en los tres convenios estatales suscritos para el sector de prensa diaria, desde los que se insta a las empresas del sector a poner en marcha estatutos de redacción. Tampoco se menciona en los convenios de los diarios El País y El Mundo ni en los de la Corporación RTVE y la Agencia EFE, que cuentan con estatutos de redacción donde se contempla y desarrolla este derecho profesional.

Un caso particular son los convenios del sector de prensa no diaria, hasta el más reciente de 2008. En concreto, el convenio colectivo suscrito en 1996 incluía un artículo dedicado a la cláusula de conciencia, que queda suprimida en el convenio suscrito en 2008.

Sí se encuentra expresamente recogida la cláusula de conciencia en los convenios colectivos de dos agencias de noticias: Europa Press y Servimedia. En el de la Agencia EFE se encuentra formulado en relación con los derechos sobre la firma.

\subsection{Derechos de autor}

Recuerda Díaz Arias que ya la I Convención de Periodistas de España, celebrada en Cádiz en abril de 1998, reclamaba la adopción de medidas concretas de protección de los derechos materiales y los derechos morales de los periodistas y recomendaba, en particular, la inclusión en los convenios de los medios de comunicación, de fórmulas que garanticen el respeto por los derechos morales y los derechos materiales de los periodistas como autores, así como la incorporación de normas que prevean la reutilización de sus obras en el seno de empresas multimedia (2000: 146,147).

Por lo que se refiere a los convenios colectivos estudiados, no aparece referencia a los derechos de propiedad intelectual en los convenios estatales de Prensa Diaria, Prensa no Diaria y Radio Comercial, ni en los particulares de El País, CRTVE, Cuatro, Antena 3 Televisión, La Ser (Unión Radio) y Onda Cero (Uniprex).

Tampoco hay referencia a los derechos de propiedad intelectual en el convenio colectivo de EFE, pero sí en su Estatuto de Redacción, cuyo art.24 establece lo siguiente: "Los profesionales de EFE tienen derecho a la propiedad intelectual del producto de su trabajo, cuyos derechos de explotación ceden a la empresa a cambio de sus emolumentos".

Los convenios de Europa Press y Colpisa, por su parte, recogen de manera expresa la cesión a la empresa de la totalidad de los derechos de explotación, con carácter exclusivo y universal (para todos los países, soportes y sistemas de difusión), incluida la posibilidad de que la empresa ceda a terceros dichos derechos de explotación. El convenio de El Mundo, en esa línea, remite al art.51.2 de la Ley de Propiedad Intelectual, sin concretar de manera tan precisa como las agencias citadas, la universalidad de la cesión.

\subsection{Derechos sobre la firma}

Además de los derechos materiales o patrimoniales sobre su obra que, como hemos visto, pueden dar lugar o no a retribución en función de lo que haya sido pactado o no pactado entre el trabajador y la empresa, el periodista retiene sobre su obra unos derechos morales que son irrenunciables e inalienables, y entre los que se incluye el de 
negarse a que su nombre aparezca como autor en caso de disparidad de criterios con el director o si éste decide modificar o deformar su contenido (De Carreras 2008: 306). Este conjunto de posibilidades llevan a Díaz Arias a concluir que "muchas manipulaciones informativas podrían ser resistidas invocando el derecho irrenunciable e inalienable del periodista [...] a exigir el respeto a la obra y a impedir cualquier deformación, modificación, alteración o atentado contra ella" (2000: 143).

Estos derechos sobre la firma no aparecen recogidos en ninguno de los convenios estatales y, dentro de los convenios particulares, solamente se mencionan en los de EFE y Colpisa.

\subsection{Derecho al secreto profesional}

Una de las cuestiones fundamentales que permanecen abiertas en relación con la aplicación del secreto profesional en el ámbito de la información periodística en nuestro país es la relativa al sujeto titular de este derecho, como ya veíamos al tratar el tema de la identidad de los periodistas. Para Azurmendi, no cabe duda de que el sujeto del secreto profesional es el periodista (Azurmendi, 2001: 184,185). De Carreras, por su parte, realiza un interesante análisis sobre quiénes son los titulares del derecho-deber al secreto profesional a partir de la literatura comparada sobre concepto e identidad del periodista en el ámbito jurídico y señala que son siempre sujetos de este derecho los periodistas en relación laboral con la empresa informativa; también, los colaboradores permanentes, los reporteros autónomos y los colaboradores que hayan accedido a la identidad de una fuente que no debe ser identificada. No son considerados sujetos del derecho al secreto profesional los colaboradores circunstanciales (2008: 330,331).

Como sucedía con los otros derechos profesionales analizados, el relativo al secreto profesional aparece escasamente recogido en los convenios colectivos del sector. No aparece en los convenios estatales ni en la mayoría de los convenios particulares, con excepción de los de Europa Press, Servimedia, y El País.

\subsection{Estatutos de Redacción}

Los estatutos de redacción son pactos voluntarios entre la empresa informativa y los periodistas que en ella trabajan, mediante los cuales se reconocen una serie de derechos profesionales y se incorporan mecanismos de representación que adoptan la forma de comités o consejos elegidos por los miembros de la redacción, colectivo integrado, a estos efectos, por todos aquellos profesionales cuya actividad implica, de una u otra manera, "intervenir en el proceso de producción informativa de forma decisoria sobre los contenidos del objeto informativo" (Carrillo, 1997:61).

Para Escobar Roca, estos estatutos de redacción son el necesario complemento de los convenios colectivos, como mecanismo para "una adecuada distribución de funciones entre la empresa y los periodistas, cuya natural posición de inferioridad debería encontrar un adecuado estatuto privilegiado a favor de los comités de redacción" (2002: 160). Azurmendi coincide con este planteamiento, al señalar que "pueden constituirse en una defensa frente al servilismo ocasionado por la relación laboral" (2001: 226).

Escobar de la Serna, por su parte, insiste en la necesidad de distinguir el ámbito de los convenios colectivos, que es el de las relaciones de carácter laboral, del de los es- 
tatutos de redacción, pactos entre empresa y trabajadores que, para este autor, en ningún caso tienen consecuencias laborales, aunque sí puedan tener efectos normativos en la medida en que regulan, entre otras cuestiones, los derechos y deberes de los periodistas, el secreto profesional, la cláusula de conciencia, el poder sobre el producto informativo del director o de la redacción, etc. (1997: 233,234). Díaz Arias (2003: 11) va más allá e indica que, además de tener efectos normativos, si forman parte del convenio colectivo, tienen su misma fuerza vinculante e incluso pueden tener incidencia laboral, (por ejemplo, si establecen determinados requisitos o habilidades para ser considerados como informadores).

El I Convenio Estatal de Prensa Diaria, suscrito en 2001, incluye una recomendación final a las empresas para que pongan en marcha estatutos de redacción "como forma de regular las relaciones profesionales del colectivo de redactores con la Dirección de las empresas afectadas" $\left(\mathrm{DT} 3^{\mathrm{a}}\right)$. Esta recomendación se ha mantenido en los dos convenios posteriores.

Entre las escasas empresas que cuentan con estatuto de redacción, solamente una, la Agencia EFE, ha vinculado su Estatuto de Redacción al convenio colectivo, como una parte indisociable de éste y con su misma exigibilidad. En las otras tres empresas, de entre todas las analizadas, que cuentan con estatuto de redacción -El País, El Mundo y la Corporación RTVE- en el que se recogen los derechos y deberes de los periodistas y se establecen mecanismos de representación y relación de la redacción con la dirección, este instrumento no tiene vinculación con el convenio colectivo.

\section{Conclusiones}

La presencia y representación de los periodistas en los convenios colectivos de las empresas que actúan en el ámbito de la producción y difusión de contenidos informativos oscila entre dos extremos. En uno de éstos asistimos a la extinción del término "periodista" como identificador nominal de un tipo de profesional que tiene como ocupación habitual una actividad de carácter intelectual consistente en la obtención, elaboración, tratamiento y difusión de información. En el otro extremo, de menor peso y dimensiones, algunos convenios intentan recuperar y actualizar el concepto, adaptándolo a los nuevos retos y exigencias de un universo informativo que poco tiene que ver, desde una perspectiva tecnológica, organizativa y de producción, con los medios del siglo pasado. Y entre ambos extremos, en una zona intermedia cuya mancha es cada vez mayor, la identidad del periodista se desdibuja y difumina en los sistemas de clasificación profesional adoptados por muchas empresas informativas.

Por otra parte, lo que el periodista hace en el seno de una empresa informativa, el tipo de tareas que realiza y las labores que le ocupan, contribuye de manera decisiva a configurar un área de actividad diferenciada de otras que puedan existir en la empresa informativa (distribución, gestión, comercial, etc.). En algunos convenios colectivos ni siquiera existe ya esa área de actividad, tradicionalmente llamada "Redacción", ausencia que podría ser sintomática de una pérdida del sentido de misión en determinadas empresas periodísticas.

Por lo que se refiere a los criterios de clasificación y organización profesional dentro de la empresa informativa, es decir, qué puestos ocupa el periodista en el seno de 
estas organizaciones, en los convenios particulares de algunas (escasas) empresas periodísticas, se siguen manteniendo categorías y perfiles profesionales claramente periodísticos. Sin embargo, en los convenios sectoriales y, por influencia de éstos, en los particulares de muchas otras empresas, se han consolidado criterios de clasificación profesional que permiten poca, si no ninguna, diferenciación de los periodistas y sus categorías propias.

Y si atendemos a los derechos profesionales a la cláusula de conciencia, al secreto profesional, a los derechos de autor y a los derechos sobre la firma, comprobamos que están ausentes, de manera general, en los textos resultantes de la negociación colectiva.

\section{Referencias bibliográficas}

ASOCIACIÓN DE LA PRENSA DE MADRID (2004, 2005, 2012): Informe anual de la profesión periodística. Madrid.

AZURMENDI, Ana (2001): Derecho de la información. Guía práctica para profesionales de la comunicación. Pamplona, EUNSA.

CALLEJO, Javier (20002): “Medios, género, poder”, en GARCÍA DE CORTÁZAR, Marisa y GARCÍA DE LEÓN, Ma Antonia (coords.): Profesionales del periodismo. Hombres y mujeres en los medios de comunicación. Madrid, Centro de Investigaciones Sociológicas, Colección Monografías, nº 81, pp. 1-30.

CANEL, María José; RODRÍGUEZ ANDRÉS, Roberto; y SÁNCHEZ ARANDA, José Javier (2000): Periodistas al descubierto. Retrato de los profesionales de la información. Madrid, Centro de Investigaciones Sociológicas, Colección Opiniones y Actitudes, $\mathrm{n}^{\circ} 33$.

CARRERAS SERRA, Luis (2008): Las normas jurídicas de los periodistas. Derecho español de la información. Barcelona, UOC.

CARRILLO, Marc (1993): La cláusula de conciencia y el secreto profesional de los periodistas. Una aproximación al estatuto jurídico de los profesionales de la información. Barcelona, Civitas.

CARRILLO, Marc (1997): "Los estatutos de redacción, la cláusula de conciencia y el secreto profesional", en ESCOBAR DE LA SERNA, Luis: La cláusula de conciencia. Madrid, Universitas, pp. 53-64.

CUADERNOS DE PERIODISTAS (2010):“Los periodistas ganaron 35.000 euros al año de media en España". Madrid, APM (Asociación de la Prensa de Madrid), marzo, pp. 7-37.

DEL VAL, Consuelo (2000): "Imágenes de la profesión", en GARCÍA DE CORTÁZAR, Marisa y GARCÍA DE LEÓN, $\mathrm{M}^{\mathrm{a}}$ Antonia (coords.). Profesionales del periodismo. Hombres y mujeres en los medios de comunicación. Madrid, Centro de Investigaciones Sociológicas, Colección Monografías, nº 81, pp. 145-172.

DÍAZ ARIAS, Rafael (2000): "Algunos aspectos de los derechos de autor de los periodistas en España”. Documentación de las Ciencias de la Información, $\mathrm{n}^{\circ}$ 23, pp. 141-147. 
DIAZ ARIAS, Rafael (2003): Derecho de la Información. Barcelona, Ariel.

DIAZ ARIAS, Rafael (2008): "El nuevo Estatuto de Información de la Corporación RTVE: independencia editorial e independencia profesional en un marco deontológico". VI Congreso Internacional de Ética y Derecho de la Información, Valencia, 7 y 8 de noviembre

DIAZ NOSTY, Bernardo (2011): Libro negro del periodismo en España. Madrid, APM (Asociación de la Prensa de Madrid)

ESCOBAR DE LA SERNA, Luis (1997): Manual de Derecho de la Información. Madrid, Dykinson.

ESCOBAR ROCA, Guillermo (2002): Estatuto de los periodistas. Régimen normativo de la profesión y organización de las empresas de comunicación. Madrid, Tecnos.

ESCOBAR ROCA, Guillermo (2003): "Regulaciones y déficit de una profesión emblemática. El Derecho de los periodistas". Telos. Cuadernos de Comunicación e Innovación, $\mathrm{n}^{\mathrm{o}} 54$, enero-marzo, en: http://telos.fundaciontelefonica.com/telos /articulocuaderno.asp@idarticulo=5\&rev=54.htm

FERNÁNDEZ AREAL, Manuel (2010): "Una profesión titulada Periodismo". Revista Latina de Comunicación Social, $\mathrm{n}^{\mathrm{0}} 65$

FERNÁNDEZ FERNÁNDEZ, Pablo Alfonso (2009): Estatuto jurídico del profesional de la información. Los colegios profesionales de periodistas. Tesis doctoral. Universidad Complutense de Madrid.

GILLMOR, Dan (2006): We the Media. Grassroots Journalism by the People, for the People. Sebastopol, O'Reilly Media.

HANITZSCH, Thomas et al. (2012): "Worlds of Journalism. Journalistic Cultures, Professional Autonomy, and Perceived Influences across 18 Nations", en WEAVER, David \& H, WILLNAT, Lars (editors): The Global Journalist in the 21st Century. New York, London, Routledge, pp. 473-494.

HUMANES, Maria Luisa (2003): "Evolución de roles y actitudes. Cultura y modelos profesionales del periodismo". Telos. Cuadernos de Comunicación e Innovación. $\mathrm{n}^{\mathrm{o}}$ 54, enero-marzo, en: http://telos.fundaciontelefonica.com/telos/articulocuaderno.asp@idarticulo=3\&rev=54.htm

KOVACH, Bill \& ROSENSTIEL, Tom (2010): Blur. How to Know What's True in the Age of Information Overload. New York, Bloomsbury.

LABIO BERNAL, Aurora (2001): "La profesión periodística ante los intereses de la estructura informativa. Una aproximación al tema". Ámbitos, $\mathrm{n}^{\circ}$ 6, pp. 81-94.

LÓPEZ VIDALES, Nereida y ORTIZ SOBRINO, Miguel Ángel (2011): "Viejas nomenclaturas, nuevas competencias. Perfiles profesionales en la radio española". Telos. Cuadernos de Comunicación e Innovación, $\mathrm{n}^{\circ}$ 87, abril-junio, pp. 63-87.

MURO BENAYAS, Ignacio (2010): "La deconstrucción de la mediación informativa. Crisis de medios y revolución en la cadena de valor noticioso". Telos. Cuadernos 
de Comunicación e Innovación, $\mathrm{n}^{\mathrm{o}} 84$, julio-septiembre, en: http://telos.fundaciontelefonica.com/seccion $=1268 \&$ idioma $=$ es_ES\&id $=2010072908420001 \&$ activo $=6$.do

OLMOS, Víctor (2011): La Casa de los Periodistas. Asociación de la Prensa de Madrid 1979-2010. Madrid, Ediciones APM

REAL RODIGUEZ, Elena (2005): “La condición de periodista en la red”. III Congrés Internacional Comunicació i realitat. La Utopía digital en los medios de comunicación: de los discursos a los hechos. Barcelona, Facultat de Ciències de la Comunicació Blanquerna, Universitat Ramon Llull.

REAL RODRIGUEZ, Elena (2006): "Periodistas sin identidad profesional: puntualizaciones al proyecto para un futuro Estatuto", Ámbitos, no 15, pp. 333-361.

ROSES, Sergio, FARIAS BATLLE, Pedro (2013): "Comparison between the professional roles of Spanish and U.S. journalists: Importance of the Media System as the Main Predictor of the Professional Roles of a Journalist". Comunicación y Sociedad, Vol XXVI, nº1, pp. 170-195.

SÁNCHEZ ILLÁN, Juan Carlos (2005): "El perfil profesional del periodista español. Evolución reciente y nuevos desafíos (1990-2005)". Telos. Cuadernos de Comunicación e Innovación, $\mathrm{n}^{\mathrm{o}} 63$, abril-junio, en: http://telos.fundaciontelefonica.com /telos/articulocuaderno.asp@idarticulo=5\&rev=63.htm

SCOLARI, Carlos Alberto et al. (2008): "El periodista polivalente. Transformaciones en el perfil del periodista a partir de la digitalización de los medios audiovisuales catalanes". Zer, vol. 13, n. 25, pp. 37-60.

SORIA, Carlos (1989): La crisis de identidad del periodista. Barcelona, Mitre, 1989.

SUÁREZ VILLEGAS, Juan Carlos (2009): "La crisis de identidad del periodista y la ética profesional". Estudios sobre el Mensaje Periodístico, vol. 15, pp.119-134. Madrid, Servicio de Publicaciones de la Universidad Complutense.

SUÁREZ VILLEGAS, Juan Carlos, JIMÉNEZ, Eva (2012): “La identidad de los periodistas españoles, entre el ideal y la realidad. Análisis de las intervenciones parlamentarias realizadas en el Congreso de los Diputados en 1994 y 2004". Anàlisi, $\mathrm{n}^{\mathrm{o}} 47$, pp. 1-18.

UGLAND, Erik, HENDERSON, Jennifer (2007): "Who is a Journalist and Why Does it Matter? Disentangling the Legal and Ethical Arguments". Journal of Mass Media Ethics, vol. 22, no 4, pp. 241-261. 